REVESCO. Revista de Estudios Cooperativos

ISSN: $1885-8031$

http://dx.doi.org/10.5209/REVE.56133

\title{
Efectos de la crisis económica sobre el emprendimiento en empresas de economía social en España: un análisis espacial ${ }^{1}$
}

\author{
Santiago Cantarero ${ }^{2}$, Miguel González-Loureiro ${ }^{3}$ y Francisco Puig ${ }^{4}$
}

Recibido: 22 de julio de 2016 / Aceptado: 12 de enero de 2017

Resumen. En los últimos años, la desfavorable evolución de la coyuntura económica ha provocado intensos cambios estructurales y espaciales en la creación de empresas que cuestionan la validez de algunos supuestos básicos sobre dinámica emprendedora y desarrollo territorial. Por ello, el objetivo de este trabajo es analizar la existencia de patrones espaciales de creación de empresas de economía social en España y estudiar su evolución temporal durante dos etapas de intensos cambios: una de crecimiento (2002-2007) y otra de profunda crisis generalizada (2008-2013).

A partir de la definición de un índice de agrupación de empresas de economía social aplicamos técnicas estadísticas basadas en econometría espacial (índice de Moran y LISA). Para tal fin se tomaron datos longitudinales del número de empresas creadas en España, durante el período 20022013, bajo las fórmulas de economía social y mercantil comparándose posteriormente a nivel autonómico. Su dinámica se analiza conjuntamente con el PIB regional como indicador del contexto económico.

Los resultados más generales apuntan a que el patrón de expansión de la dinámica emprendedora en empresas de economía social es negativo y regionalmente heterogéneo, mostrando la existencia de algunas concentraciones espaciales, en lo que podrían denominarse Clusters de Empresas de Economía Social. A la vista de esos resultados y patrones se evidencia una erosión en la influencia de determinados factores de tipo contextual (tradición, cultura y normativa) en esa actividad emprendedora. Nuestras contribuciones tienen implicaciones para la academia y para los decisores de políticas públicas de apoyo a la creación de empresas y la economía social.

Palabras clave: Emprendimiento; Regiones; Economía Social; Índice de Moran; Cluster.

Claves Econlit: R10; R30; R50.

\section{[en] Effects of the economic crisis on entrepreneurship in social economy companies in Spain: a spatial analysis}

Abstract. In recent years, the unfavorable evolution of the economic situation has provoked intense structural and spatial changes in the creation of companies that question the validity of some basic assumptions about entrepreneurial dynamics and territorial development. Therefore, the objective of this paper is to analyze the existence of spatial patterns of creation of social economy enterprises in

1 Este trabajo se ha beneficiado de las Ayudas para Acciones Especiales de Investigación de la Universitat de València (UV-INV-AE16-488900)

2 Universitat de València, España

Dirección de correo electrónico: santiago.cantarero@uv.es

3 Universidad de Vigo, España

Dirección de correo electrónico: mloureiro@uvigo.es

4 Universitat de València, España

Dirección de correo electrónico: francisco.puig@uv.es 
Spain and to study their temporal evolution during two stages of intense changes: one of growth (2002-2007) and another of deep generalized crisis (2008-2013).

Based on the definition of a cluster index of social economy companies we apply statistical techniques based on spatial econometrics (Moran and LISA index). For this purpose, longitudinal data were taken from the number of companies created in Spain, during the period 2002-2013, under the formulas of social and mercantile economy, comparing later to the autonomic level. Its dynamics are analyzed together with regional GDP as an indicator of the economic context.

The more general results indicate that the pattern of expansion of entrepreneurial dynamics in social economy enterprises is negative and regionally heterogeneous, showing the existence of some spatial concentrations in what could be called Clusters of Social Economy Companies. In view of these results and patterns, an erosion in the influence of certain contextual factors (tradition, culture and regulation) on this entrepreneurial activity is evident. Our contributions have implications for academia and policy makers in support of business start-ups and the social economy.

Keywords: Entrepreneurship; Countries; Social economy; Moran's index; Cluster.

Sumario. 1. Introducción. 2. Aproximación al objeto de estudio. 3. Metodología. 4. Análisis y discusión de resultados. 5. Conclusiones. 6. Referencias bibliográficas.

Cómo citar: Cantarero, S., González-Loureiro, M. y Puig, F. (2017) Efectos de la crisis económica sobre el emprendimiento en empresas de economía social en España: un análisis espacial. REVESCO. Revista de Estudios Cooperativos, No 125, pp. 24-47. DOI: 10.5209/REVE.56133.

\section{Introducción ${ }^{5}$}

El surgimiento de empresas y su mortalidad no suele responder a un patrón aleatorio en términos geográficos (Glaeser et al, 2010). Más bien, responde a una miríada de factores de tipo contextual (ciclo económico, nivel de desarrollo socioeconómico, nivel de factores del área), institucional (políticas públicas de apoyo) y sociológicos (orientación emprendedora, existencia de clusters) que tienen lugar en un territorio (Delgado et al, 2010; Puig et al, 2013).

Concretamente, en el ámbito de la geografía económica y la creación de empresas, el clúster o clustering (una concentración geográfica de empresas que pertenecen a un mismo sector o, en nuestro caso, a un mismo tipo de empresa, empresas de economía social) es uno de los fenómenos más estudiados. Desde los trabajos pioneros de Alfred Marshall (1923) y posteriores de Michael Porter (1999) o Giacomo Becattini (2002), se ha venido evidenciando cómo esas aglomeraciones geográficas estimulan el espíritu emprendedor. Sin embargo, recientes estudios muestran la espiral negativa de "canibalización" que una situación de crisis y declive dentro de un cluster puede tener sobre la demografía empresarial de dicha actividad económica (Staber, 2001; Potter y Watts, 2011). En otras palabras, el contexto importa (Meyer, 2015).

El comportamiento cíclico o anti-cíclico en la creación de empresas de economía social ha sido también un aspecto con resultados a veces contrapuestos. El carácter contra-cíclico aparece con fuerza en trabajos como los de Ben-Ner

5 Los autores desean agradecer los valiosos comentarios de dos revisores anónimos de REVESCO los cuales han servido para mejorar nuestro manuscrito. También deseamos reconocer la valiosa aportación del profesor Francisco Montes Suay (Universitat de València), que sin su generosidad académica este trabajo no hubiera sido posible. 
(1988), Rusell y Hanneman (1992), o Pérotin (2006) a nivel internacional y, en España, en trabajos como el de Chaves y Monzón (2012). Sin embargo, Staber (1993) señala que las empresas de economía social carecen del carácter contracíclico. En España, Grávalos y Pomares (2001) en su análisis del período 19861995 encontraron que las empresas de economía social eran contra-cíclicas. Clemente et al. (2009) encontraron en su estudio del período 1999-2007 que las empresas de economía social no mostraban la misma tendencia que el conjunto de la economía. No obstante, observaron divergencias por Comunidades Autónomas (CC.AA.), siendo más acentuado en aquellas con mayor nivel de renta per cápita y empleo. Ríos et al. (2014) en su estudio del período 1995 hasta el segundo trimestre de 2013 encontraron que, tanto en fases expansivas como recesivas, las empresas de economía social evolucionaron de manera independiente de la actividad económica, si bien sí que constataron la existencia de un cierto efecto "refugio" en etapas recesivas, que irían a favor de la hipótesis anti-cíclica.

Por lo tanto, existe la necesidad de profundizar en el conocimiento sobre la vinculación entre las fases del ciclo económico y la dinámica emprendedora de esas empresas. También sobre si existe un patrón aleatorio cuando se considera el aspecto geográfico, esto es, si podría existir un efecto "contagio" entre territorios cercanos, tanto en etapas expansivas como recesivas. O. por el contrario, podría darse un efecto concentración del emprendimiento en empresas de economía social que no se difunde en áreas circundantes., evidenciando un patrón no aleatorio. En resumen, si existen diferentes dinámicas por CC.AA. en España y si las empresas de economía social, como forma de organización de la actividad económica, se extienden a partir de núcleos en donde dichas empresas muestran una mayor resiliencia a la crisis.

Así, siguiendo a Anderson (2012), se podría argumentar que las decisiones de cada actor en un mismo territorio están interrelacionadas de manera que la decisión de uno produce efectos en otros. Así se podría analizar y predecir de forma espacial determinados patrones de comportamiento como puede ser la creación de empresas de economía social. Si esta relación es positiva, se podría predecir que ejercerá una cierta atracción o imitación, y que emergerán clusters. Si por el contrario se produce un efecto negativo, la actividad o el fenómeno analizado estará disperso en el espacio, mientras que en otras situaciones intermedias cabe esperar un cierto patrón aleatorio.

Por tanto, el objetivo de este trabajo es analizar si existe algún patrón espacial de creación de empresas de economía social por CC.AA. en España, así como su evolución temporal. De esta manera se contará con más información que permita realizar predicciones sobre cómo evolucionará dicho patrón espacial. De haber un patrón geográfico, se podrá identificar posteriormente qué rasgos espaciales han podido influir en dicho patrón. Para ello, distinguiremos dos etapas: a) de crecimiento (2002-2007) y b) de profunda crisis generalizada (2008-2013).

Esta investigación tiene implicaciones tanto académicas como políticas al arrojar alguna luz sobre la interacción entre el contexto socioeconómico y el tipo de empresa creada por los emprendedores. Es importante constatar si existen CC.AA. con mayor éxito que otras en la promoción de este tipo de empresas. De esta forma, se podrían validar las acciones de promoción de estas figuras societarias que se han llevado a cabo en las CC.AA. de mayor éxito. También 
facilitaría identificar las normas definidas para su regulación y poder evaluar si el marco normativo ha podido tener algún efecto en la distribución geográfica en futuras investigaciones. Para tal fin, nuestro trabajo se articula en torno a cuatro grandes epígrafes. A continuación, introducimos algunos aspectos conceptuales sobre clusters y sobre emprendimiento de empresas de economía social. Posteriormente, desarrollamos la metodología de esta investigación, mientras que en un siguiente apartado detallamos y discutimos los resultados obtenidos. En la última sección, presentamos las principales conclusiones y limitaciones, así como líneas de investigación futuras.

\section{Aproximación al objeto de estudio}

Algunas de las razones que explican la desfavorable evolución del emprendimiento en los clusters tienen su origen en la competencia interna en unas determinadas industria y área geográfica. Cuando entra en declive, se enfatizan estrategias basadas en precios (Delgado et al., 2010) que provocan un efecto expulsión de la actividad empresarial hacia mercados de aprovisionamiento internacionales (Puig et al., 2014). Además, la dinámica observada en la densidad de empresas especializadas en torno a una materia prima, producto o servicio en una localización concreta genera también efectos psicológicos y sociológicos a nivel de emprendimiento mediante el mecanismo "imitación". Esto es, el emprendedor, ante la incertidumbre sobre si sus decisiones serán las correctas en el más puro sentido knightiano (Knight, 1921), tiende a imitar las experiencias que otros han desarrollado ya con éxito. Este mecanismo explicaría la existencia de un cierto patrón en el surgimiento de empresas. Por tanto, la clave sería detectar primero dichos patrones exitosos.

Recientes estudios han demostrado que las denominadas empresas vinculadas a la economía social ${ }^{6}$ ofrecen ventajas en cuanto a su supervivencia respecto a las tradicionales formas mercantiles (Monzón y Chaves, 2012; Cantarero et al., 2013; González-Loureiro et al., 2014). Estas empresas de carácter privado y autónomo en cuanto a decisión y libertad de adhesión, surgen para satisfacer las necesidades de sus socios mediante la producción de bienes y servicios. Se caracterizan por el proceso de toma de decisión y la manera en que deciden la distribución de sus beneficios y/o excedentes, que es de carácter democrático y participativo, en donde cada socio tiene la misma proporción de poder. (Monzón y Chaves, 2012). Otra característica es que alguno de sus grupos de interés o stakeholders contribuye al desarrollo de la actividad empresarial de una doble manera: primero, en su condición de stakeholder cercano mediante las transacciones habituales; y segundo, adquiriendo la condición de socio de la empresa (Chaves y Monzón, 2012). Fundamentalmente, estos stakeholders suelen ser proveedores, clientes o los propios trabajadores de la empresa. En este estudio trataremos de analizar el

6 Por empresas de economía social se entienden las cooperativas y las sociedades laborales. Las Mutuas, los centros especiales de empleo o de inserción entre otras, son sociedades de economía social que se rigen por los mismos principios pero que no tienen ánimo de lucro. 
amplio espectro de esas empresas y las incluiremos a todas ellas bajo el concepto como empresas de economía social.

Desde un enfoque de teoría institucional (North, 1993), para que una organización se convierta en una institución ${ }^{7}$ en un territorio y luego contagie a territorios cercanos de manera isomorfa, primero debe legitimar su existencia. Sin embargo, la literatura sobre economía social y emprendimiento raras veces adopta este enfoque institucional mediante estudios longitudinales y geoespaciales en los cuales se centre la atención sobre el mecanismo de la imitación para la legitimación.

Por otro lado, Glaeser et al. (2010) sugiere la existencia de una dependencia en la trayectoria (path-dependence): cuando un territorio ofrece alguna ventaja de tipo geoespacial y su sistema de instituciones es eficaz en el apoyo al emprendimiento, surgirán entonces clusters de emprendedores de características similares a los existentes en etapas previas. Por lo tanto, su dinámica dependerá de las elecciones realizadas por los agentes en etapas iniciales. Dichos clusters se basarán en las relaciones cliente-proveedor entre esas nuevas empresas surgidas (input-output linkages), en la existencia de un mercado de trabajadores especializados o cualificados especialmente para dichas actividades en el territorio (labor market pooling) y en el conocimiento clave compartido para el arranque y organización de la nueva empresa instrumentalizado a través del sistema institucional especializado (knowledge spillovers). A esto, habría que añadir el enfoque psicosociológico: ante la incertidumbre que supone el crear una nueva empresa los emprendedores tenderán a imitar y replicar en ese territorio experiencias que hayan tenido éxito en períodos anteriores. Por tanto, si en una determinada región se observa que las empresas de economía social sobreviven más que otro tipo de empresas (tradicionalmente las mercantiles bajo fórmulas de sociedades limitadas, sociedades anónimas, etc.), entonces los emprendedores tenderán a imitar ese comportamiento adoptando dichas formas en etapas posteriores.

La aglomeración de empresas en un determinado espacio geográfico genera efectos positivos a nivel sociológico mediante aquel mecanismo de imitación. Esto es, en el momento en que una iniciativa empresarial o una región comienzan a destacar en algún aspecto relacionado con el emprendimiento, generará un efecto llamada a corto plazo. Es por ello que podemos justificar que en el momento en que una determinada forma de organizar la actividad empresarial tenga mayor éxito que otras iniciativas, entonces podrá comenzar a generarse un clúster de empresas basadas en dicha forma organizativa. Dado que las empresas de economía social son un ejemplo de éxito en la supervivencia empresarial (Cantarero et al., 2013), parece un buen punto de partida para explorar si el surgimiento de áreas geográficas con creciente especialización en dichas formas organizativas está produciendo o puede producir un efecto llamada y conformar lo que se denominarían cluster de empresas de economía social. Este tipo de cluster se correspondería con la tipología de cluster de "red social" según la taxonomía de Gordon y McCann (2005), en el que el tamaño de empresas es variable, las

Según el Diccionario de la RAE (2014), en su acepción $2^{\mathrm{a}}$ se puede entender una institución como "cosa establecida o fundada", lo cual coincide con el sentido dado por la teoría institucional a las instituciones, quienes van adquiriendo legitimidad mediante la aceptación extensión de su uso. 
relaciones se basan esencialmente en la confianza, lealtad y en la existencia de un lobby conjunto.

Un enfoque sociológico adicional puede derivarse de la anterior argumentación a partir de la teoría del nodo débil de Granovetter (1973). Bajo este enfoque, aquellos emprendedores que tienen vínculos más débiles con su entorno son los que mayor necesidad tienen de organizarse en ese tipo de clusters para mejorar su nivel relacional. Las empresas de economía social han sido tradicionalmente poco contempladas como alternativas a considerar por los emprendedores, esencialmente porque existe un grado de conocimiento realmente bajo acerca de sus especiales características (Chaves y Monzón, 2012; Bel-Durán et al., 2016). El desconocimiento de este tipo de empresas les añade una percepción negativa por parte de nuevos emprendedores, optando éstos por formas de tipo mercantil más reconocidas en su ámbito (Martín et al., 2013).

Numerosos estudios han encontrado que las empresas de economía social son más longevas y resistentes que sus contrapartes mercantiles, especialmente en etapas de crisis (Ben-Ner, 1988; Rusell y Hanneman, 1992; Pérotin, 2006; Chaves y Monzón, 2012). Además, durante las etapas de crisis, el creciente número de desempleados tiende a considerar la posibilidad de autoempleo y trata de reducir el riesgo asociado a emprender mediante el uso de fórmulas cooperativas (Ríos et al., 2014). A pesar de esa evidencia, todavía la empresa de economía social no es la opción mayoritariamente preferida por los emprendedores, lo que implica una cierta paradoja. Todo ello hace pensar que la creación de empresas de economía social sigue un patrón espacial no aleatorio a lo largo del tiempo y la geografía. A su análisis dedicamos los siguientes apartados.

\section{Metodología}

En base al objetivo planteado, nuestro trabajo se centra en la población de empresas que se han creado en España en el período de 2002-2013. La población se clasificó en dos grandes tipos de empresas: aquellas de carácter mercantil y las empresas de economía social (cooperativas y sociedades laborales). Las razones del período, ámbito geográfico y forma jurídica obedecen a razones metodológicas, de disponibilidad de datos y de control del sistema institucional de cada región.

La información se obtuvo de tres fuentes diferentes. Primero, y con respecto al número de empresas creadas tanto de economía social como de carácter mercantil, se ha recurrido a las bases de datos del Ministerio de Empleo y Seguridad Social, en el apartado correspondiente a las altas de empresas en los Códigos de Cuenta de Cotización. Segundo, a los efectos de contraste de esa información se recurrió a las bases de datos SABI y Orbis con el fin último de verificar la bondad de los datos obtenidos de manera que garantizase un estudio representativo y fiable de la realidad. Tercero, con respecto a los datos del PIB, éstos se extrajeron de la base de datos del INE a partir de las cuentas de la contabilidad regional y nacional realizados por esta institución y el Banco de España.

Desglosamos el período temporal en dos sub-períodos. Uno del 2002 al 2007, caracterizado por fases de crecimiento de la economía. Un segundo sub-período está referido del 2008 al 2013, caracterizado como etapa de crisis y post-crisis que 
recoge el contexto de depresión económica. Esta diferenciación temporal se establece como una obligación para poder evaluar y calcular la existencia de clusters de empresas de economía social y la actitud emprendedora en las diferentes CC.AA. considerando el ciclo económico y el contexto sociocultural.

Para la ejecución de este trabajo se utilizaron los programas gvSIG y GEODA, siguiendo las propuestas desarrolladas por Anselin $(1995,2004)$ y recogidas en el GeoDa Center for analysis and computation ${ }^{8}$. Estos programas permiten el estudio espacial de la información y reportan resultados gráficos que facilitan su interpretación.

También se aplican dos índices: el Índice Global de Moran (1950) y el Índice de Asociación Local (LISA), que ayuda a la interpretación de los resultados obtenidos con el índice anterior. Ambos permiten valorar la existencia de autocorrelación espacial. El cálculo de dichos índices se realizó a partir de los datos obtenidos del Ministerio de Empleo y Seguridad Social.

El método trata de determinar si el proceso de emprendimiento social es propio de un territorio y se concentran exclusivamente en él o si, por el contrario, dicho proceso tiende a difundirse en comunidades vecinas mediante el mecanismo de imitación. Se pretende también analizar si las comunidades con mayor índice se encuentran dispersas o concentradas con la intención de distinguir formas de comportamiento a la hora de emprender y su distribución espacial. Así, la valoración del Índice de Moran (método de la reina), toma valores entre $-1 \mathrm{y}+1$, indicando los extremos autocorrelaciones perfectas y que, en términos absolutos, recoge el valor explicativo del conjunto de datos geo-referenciados que se están estudiando. Cuando el valor que toma el índice de Moran es significativamente distinto de 0 , entonces se verifica la existencia de autocorrelación espacial. En caso contrario, se constata la ausencia de dicha autocorrelación y, por lo tanto, implicará que la creación de empresas de economía social sigue un patrón aleatorio en términos espaciales.

Para mapear la posible existencia de clusters de empresas de economía social, se utilizó el índice de especialización territorial o aglomeración (Iag), siguiendo el método de Staber (2001) y de Cromley y Hanink (2012), tal como se muestra en la ecuación [1]. El sentido de este indicador es valorar la presencia de un perfil de empresa en un espacio determinado (CA: Comunidad Autónoma) con respecto al total de España. Así, cuanto mayor es el índice, mayor importancia relativa tendrá el emprendimiento en empresas de economía social respecto al total en esa autonomía con respecto al mismo indicador para el global de España. Para nuestro caso, cuanto más próximo a cero sea dicho indicador, menos relevante es el carácter emprendedor basado en economía social.

8 http://GeoDacenter.asu.edu. GeoDa es un software SIG gratuito que permite el estudio de variables georeferenciadas y el cálculo de correlaciones y regresiones espaciales. 


\section{Total empresas economía social creadas nivel CCAA

$[1](\mathrm{Iag})=\frac{\text { Total empresas creadas a nivel CCAA }}{\text { Total empresas economía social creadas en España }}$ \\ Total empresas creadas en España}

\section{Análisis y discusión de resultados}

\subsection{Dinámica de creación: empresas de economía social vs. empresas mercantiles}

La diferente evolución de la economía en los últimos 15 años se ve constatada en las tasas de emprendimiento. De acuerdo a la tabla (1), el período 2008-2013 se caracteriza por ser un período de contracción económica. Lleva aparejado la destrucción de empresas, así como una ralentización en el proceso de constitución de nuevas empresas, especialmente en comparación con el período expansivo anterior (2002-2007). Desde la perspectiva de las formas organizativas, se constata que la contracción es mucho más intensa entre las empresas de economía social. Así, las tasas de reducción en algunas comunidades autónomas fueron de hasta el 81,61\% (Castilla La Mancha), frente a tasas máximas de reducción de empresas mercantiles que toman valores en torno al $20 \%$. En términos generales, los datos muestran que la situación de crisis ha afectado más a la creación de empresas de economía social frente al de las formas mercantiles tradicionales (SA, SL).

Tabla. 1. Evolución de las empresas creadas según forma jurídica y comunidad autónoma9 9

\begin{tabular}{|l|c|c|c|c|c|c|}
\hline \multicolumn{1}{c}{ Comunidad } & \multicolumn{3}{c|}{ Empresas Economía Social } & \multicolumn{2}{c|}{ Empresas Mercantiles } \\
\cline { 2 - 7 } & $\begin{array}{c}\mathbf{2 0 0 2 -} \\
\mathbf{0 7}\end{array}$ & $\mathbf{2 0 0 8 - 1 3}$ & $\begin{array}{c}\text { \% } \\
\text { variación }\end{array}$ & $\mathbf{2 0 0 2 - 0 7}$ & $\mathbf{2 0 0 8 - 1 3}$ & $\begin{array}{c}\text { \% } \\
\text { variación }\end{array}$ \\
\hline ANDALUCIA & 9160 & 2670 & $-70,85 \%$ & 226510 & 239648 & $\mathbf{5 , 8 0 \%}$ \\
\hline ARAGÓN & 1046 & 411 & $-60,71 \%$ & 35425 & 29242 & $-17,45 \%$ \\
\hline ASTURIAS & 766 & 387 & $-49,48 \%$ & 26354 & 21069 & $-20,05 \%$ \\
\hline BALEARES & 370 & 144 & $-61,08 \%$ & 36529 & 30775 & $-15,75 \%$ \\
\hline CANARIAS & 864 & 248 & $-71,30 \%$ & 61412 & 51977 & $-15,36 \%$ \\
\hline CANTABRIA & 148 & 47 & $-68,24 \%$ & 15477 & 12292 & $-20,58 \%$ \\
\hline C. LA MANCHA & 1838 & 338 & $-81,61 \%$ & 57191 & 49891 & $-12,76 \%$ \\
\hline $\begin{array}{l}\text { CASTILLA Y } \\
\text { LEÓN }\end{array}$ & 1282 & 437 & $-65,91 \%$ & 59978 & 49259 & $-17,87 \%$ \\
\hline CATALUNA & 3618 & 1371 & $-62,11 \%$ & 218086 & 174188 & $-20,13 \%$ \\
\hline $\begin{array}{l}\text { COM. } \\
\text { VALENCIANA }\end{array}$ & 3106 & 1127 & $-63,72 \%$ & 152249 & 119277 & $-21,66 \%$ \\
\hline EXTREMADURA & 551 & 227 & $-58,80 \%$ & 25322 & 28005 & $10,60 \%$ \\
\hline
\end{tabular}

9 Para evitar distorsiones estadísticas y simplificar la información ofrecida hemos excluido del estudio las ciudades autónomas de Ceuta y Melilla. 


\begin{tabular}{|l|c|c|c|c|c|c|}
\hline GALICIA & 1363 & 437 & $-67,94 \%$ & 73562 & 63078 & $-14,25 \%$ \\
\hline MADRID & 3034 & 1010 & $-66,71 \%$ & 167306 & 135680 & $-18,90 \%$ \\
\hline MURCIA & 2216 & 1089 & $-50,86 \%$ & 44493 & 34256 & $-23,01 \%$ \\
\hline NAVARRA & 497 & 251 & $-49,50 \%$ & 14620 & 12104 & $-17,21 \%$ \\
\hline PAÍS VASCO & 963 & 953 & $\mathbf{- 1 , 0 4 \%}$ & 46230 & 37365 & $-19,18 \%$ \\
\hline RIOJA (LA) & 82 & 61 & $-25,61 \%$ & 9135 & 7630 & $-16,48 \%$ \\
\hline TOTAL & $\mathbf{3 0 9 0 4}$ & $\mathbf{1 1 2 0 8}$ & $\mathbf{- 6 3 , 7 3 \%}$ & $\mathbf{1 2 6 9 8 7 9}$ & $\mathbf{1 0 9 5 7 3 6}$ & $\mathbf{- 1 3 , 7 1 \%}$ \\
\hline
\end{tabular}

Fuente: elaboración propia a partir de datos del Ministerio de Empleo y Seguridad Social (2015).

Conforme a la anterior tabla también es destacable una reducción global de la iniciativa emprendedora en empresas de economía social del -63,7\%. Mientras que en el período inicial se crearon 30.904 empresas de economía social, en el período siguiente solo se registraron 11.208. Respecto a empresas mercantiles, la reducción proporcional fue bastante inferior a la anterior (-13,7\%), pasando de 1,2 millones a 1,0 millón de empresas, aproximadamente. Por CC.AA. (NUT $\left.{ }^{10}-2\right)$, sólo el País Vasco mantuvo un ritmo de creación similar entre períodos en el caso de empresas de economía social. En el caso de las formas mercantiles, sólo crecieron entre períodos en Andalucía. En línea con Kelley et al (2012), algunas de las razones que explicarían esa evolución podrían encontrarse en el perfil del emprendedor. Ese perfil resulta diferente si atendemos a las formas organizativas y como se distribuyen en cada período observado (Tabla 2).

Tabla. 2. Distribución porcentual de las empresas creadas según forma jurídica y comunidad autónoma.

\begin{tabular}{|l|c|c|c|c|}
\hline \multicolumn{1}{|c|}{ Comunidad Autónoma } & $\begin{array}{c}\text { Econ. Social } \\
\mathbf{2 0 0 2 - 0 7}\end{array}$ & $\begin{array}{c}\text { Mercantil } \\
\mathbf{2 0 0 2 - 0 7}\end{array}$ & $\begin{array}{c}\text { Econ. Social } \\
\mathbf{2 0 0 8 - 1 3}\end{array}$ & $\begin{array}{c}\text { Mercantil } \\
\mathbf{2 0 0 8 - 2 0 1 3}\end{array}$ \\
\hline ANDALUCIA* & $29,6 \%$ & $17,8 \%$ & $23,8 \%$ & $21,8 \%$ \\
\hline ARAGÓN & $3,4 \%$ & $2,8 \%$ & $3,7 \%$ & $2,8 \%$ \\
\hline ASTURIAS & $2,5 \%$ & $2,1 \%$ & $3,5 \%$ & $2,0 \%$ \\
\hline BALEARES & $1,2 \%$ & $2,9 \%$ & $1,3 \%$ & $2,8 \%$ \\
\hline CANARIAS & $2,8 \%$ & $4,8 \%$ & $2,2 \%$ & $4,7 \%$ \\
\hline CANTABRIA & $0,5 \%$ & $1,2 \%$ & $0,4 \%$ & $1,1 \%$ \\
\hline C. LA MANCHA & $5,9 \%$ & $4,5 \%$ & $3,0 \%$ & $4,6 \%$ \\
\hline CASTILLA Y LEÓN & $4,1 \%$ & $4,7 \%$ & $3,9 \%$ & $4,5 \%$ \\
\hline CATALUÑ & $11,7 \%$ & $17,1 \%$ & $12,2 \%$ & $15,6 \%$ \\
\hline COM. VALENCIANA & $10,1 \%$ & $12,0 \%$ & $10,1 \%$ & $10,9 \%$ \\
\hline EXTREMADURA & $1,8 \%$ & $2,0 \%$ & $2,0 \%$ & $2,5 \%$ \\
\hline
\end{tabular}

10 El acrónimo NUT está derivado de las siglas en francés de Nomenclature des Unités Territoriales y son una serie de demarcaciones territoriales utilizadas por la Unión Europea con fines estadísticos, donde para el caso español la NUT-2 se correspondería a CC.AA. y la NUT-3 a provincias. 


\begin{tabular}{|l|c|c|c|c|}
\hline GALICIA & $4,4 \%$ & $5,8 \%$ & $3,9 \%$ & $5,8 \%$ \\
\hline MADRID & $9,8 \%$ & $13,2 \%$ & $9,0 \%$ & $12,4 \%$ \\
\hline MURCIA* & $7,2 \%$ & $3,6 \%$ & $9,7 \%$ & $3,2 \%$ \\
\hline NAVARRA* & $1,6 \%$ & $1,2 \%$ & $2,2 \%$ & $1,1 \%$ \\
\hline PAÍS VASCO* & $3,1 \%$ & $3,6 \%$ & $8,6 \%$ & $3,5 \%$ \\
\hline RIOJA (LA)* & $0,3 \%$ & $0,7 \%$ & $0,5 \%$ & $0,7 \%$ \\
\hline TOTAL & $100,0 \%$ & $100,0 \%$ & $100,0 \%$ & $100,0 \%$ \\
\hline
\end{tabular}

Fuente: elaboración propia a partir de datos del Ministerio de Empleo y Seguridad Social (2015).

Así, la proporción entre un tipo de empresas y otro en diferentes períodos permite comprobar si las CC.AA. que cuentan con mayor tradición en empresas de economía social mantienen su posición. Se observan comportamientos diversos. Mientras que Andalucía cambia de perfil y reduce de manera notable el porcentaje de empresas de economía social en el período de crisis, otras comunidades como Murcia, Navarra, La Rioja o País Vasco incrementan el peso de la economía social frente a empresas mercantiles. El resto mantiene perfiles casi idénticos en ambas situaciones. Estos resultados son similares al análisis cluster realizado por Pérez y Valiente (2015).

Un análisis adicional es la proporción de empresas de economía social por CC.AA. con respecto al total de empresas constituidas en cada una de ellas y la comparación de su porcentaje en ambos períodos (ver tabla 3). Los resultados indican que sólo el País Vasco mejora el porcentaje de empresas de economía social durante el período post-crisis. El resto de comunidades tiende a incrementar la proporción de empresas mercantiles de manera notable. Este hallazgo en España cuestiona la idea comúnmente aceptada desde el trabajo de Ben-Ner (1988) de que la creación de empresas de economía social es contra-cíclica, siendo un sector refugio en etapas de crisis. Parece que ese hecho no se produce cuando la etapa de crisis tiene un calado tan profundo en el tiempo y el espacio como ha sucedido durante la más reciente etapa desde el 2008. 
Tabla. 3. Porcentaje y evolución de las empresas creadas de economía social respecto al total de constituidas según periodos y comunidad autónoma.

\begin{tabular}{|c|c|c|c|c|c|c|c|}
\hline \multirow{2}{*}{$\begin{array}{l}\text { Comunidad } \\
\text { Autónoma }\end{array}$} & \multicolumn{3}{|c|}{$\begin{array}{l}\text { P1: Crecimiento } \\
(2002-2007)\end{array}$} & \multicolumn{3}{|c|}{$\begin{array}{l}\text { P2: Crisis } \\
(2008-2013)\end{array}$} & \multirow{2}{*}{$\begin{array}{c}\text { Variac. } \\
\text { de } \\
\text { peso de } \\
\text { Ec. } \\
\text { Social } \\
\text { de P1 A } \\
\text { P2 }\end{array}$} \\
\hline & $\begin{array}{l}\text { Econ. } \\
\text { Social }\end{array}$ & Mercantiles & $\begin{array}{c}\% \text { Econ. } \\
\text { Social } \\
\text { s/total }\end{array}$ & $\begin{array}{l}\text { Econ. } \\
\text { Social }\end{array}$ & Mercantiles & $\begin{array}{c}\% \\
\text { Econ. } \\
\text { Social } \\
\text { s/total }\end{array}$ & \\
\hline ANDALUCIA & 9160 & 226510 & $4,04 \%$ & 2670 & 239648 & $1,10 \%$ & $(-)$ \\
\hline ARAGÓN & 1046 & 35425 & $2,87 \%$ & 411 & 29242 & $1,39 \%$ & $(-)$ \\
\hline ASTURIAS & 766 & 26354 & $2,82 \%$ & 387 & 21069 & $1,80 \%$ & $(-)$ \\
\hline BALEARES & 370 & 36529 & $1,00 \%$ & 144 & 30775 & $0,47 \%$ & $(-)$ \\
\hline CANARIAS & 864 & 61412 & $1,39 \%$ & 248 & 51977 & $0,47 \%$ & $(-)$ \\
\hline CANTABRIA & 148 & 15477 & $0,95 \%$ & 47 & 12292 & $0,38 \%$ & $(-)$ \\
\hline C. LA MANCHA & 1838 & 57191 & $3,11 \%$ & 338 & 49891 & $0,67 \%$ & $(-)$ \\
\hline $\begin{array}{l}\text { CASTILLAY } \\
\text { LEÓN }\end{array}$ & 1282 & 59978 & $2,09 \%$ & 437 & 49259 & $0,88 \%$ & $(-)$ \\
\hline CATALUÑNA & 3618 & 218086 & $1,63 \%$ & 1371 & 174188 & $0,78 \%$ & $(-)$ \\
\hline $\begin{array}{l}\text { COM. } \\
\text { VALENCIANA }\end{array}$ & 3106 & 152249 & $2,00 \%$ & 1127 & 119277 & $0,94 \%$ & $(-)$ \\
\hline EXTREMADURA & 551 & 25322 & $2,13 \%$ & 227 & 28005 & $0,80 \%$ & $(-)$ \\
\hline GALICIA & 1363 & 73562 & $1,82 \%$ & 437 & 63078 & $0,69 \%$ & $(-)$ \\
\hline MADRID & 3034 & 167306 & $1,78 \%$ & 1010 & 135680 & $0,74 \%$ & $(-)$ \\
\hline MURCIA & 2216 & 44493 & $4,74 \%$ & 1089 & 34256 & $3,08 \%$ & $(-)$ \\
\hline NAVARRA & 497 & 14620 & $3,29 \%$ & 251 & 12104 & $2,03 \%$ & $(-)$ \\
\hline PAÍS VASCO & 963 & 46230 & $2,04 \%$ & 953 & 37365 & $2,49 \%$ & $(+)$ \\
\hline RIOJA (LA) & 82 & 9135 & $0,89 \%$ & 61 & 7630 & $0,79 \%$ & $(-)$ \\
\hline $\begin{array}{l}\text { TOTAL } \\
\text { EMPRESAS }\end{array}$ & 30904 & 1269879 & $2,38 \%$ & 11208 & 1095736 & $1,01 \%$ & $(-)$ \\
\hline
\end{tabular}

Fuente: elaboración propia a partir de datos del Ministerio de Empleo y Seguridad Social (2015)

Si además analizamos la distribución porcentual por grandes sectores de actividad en cada período (gráfico 1), se constata que durante el período de crisis (2008-2013) se incrementa la proporción de empresas dedicadas al sector servicios 
(de un $61 \%$ a un $71 \%$ ) frente al sector de la construcción (que decae de un $21 \%$ a un 13\%). La agricultura (2\%) y la industria (16\% y $14 \%)$ se mantienen relativamente estables.

Gráfico. 1. Distribución sectorial de las empresas creadas de economía social según períodos.

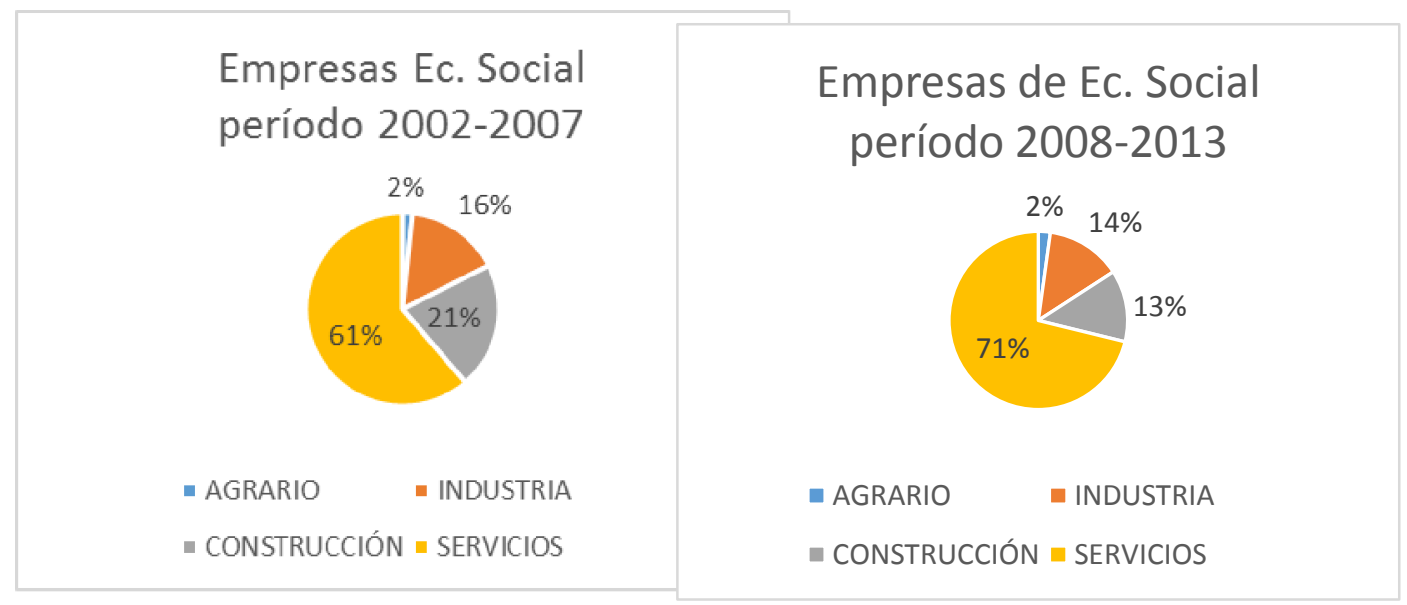

Fuente: elaboración propia a partir de datos del Ministerio de Empleo y Seguridad Social (2015).

\section{2. Índice de Localización territorial}

El análisis de los resultados a partir del Iag evidencia diferentes comportamientos (tabla 4). Así, Andalucía pasó de ser una Comunidad Autónoma con marcado carácter emprendedor en economía social en el período de crecimiento, a tener una mayor orientación al perfil de creación de empresa mercantil. El comportamiento inverso al anterior se da en la Comunidad Valenciana, Navarra y La Rioja, que pasan a tener un índice superior a 1. Sólo tres comunidades mantienen valores por encima de 1 en ambos períodos. Se trata de Aragón (que apenas cae un 15\% hasta el 1,19), Murcia (que sube un $23 \%$ hasta 4,29 ) y País Vasco (que crece un $390 \%$ hasta 4,97). Las demás mantienen valores por debajo de 1 en ambos períodos. Se pasa de cuatro CC.AA. con valores superiores a 1 en la etapa de crecimiento (20022007), a seis CC.AA. en la etapa de crisis (2008-2013). 
Tabla. 4. Índices de agrupación (Iag) de las empresas creadas de economía social según períodos y comunidad autónoma.

\begin{tabular}{|l|c|c|c|}
\hline Comunidad Autónoma & P1: 2002-2007 & P2: 2008-2013 & $\begin{array}{l}\text { Variación de P1 a } \\
\text { P2 }\end{array}$ \\
\hline ANDALUCÍA & 1,86 & 0,97 & $-47,8 \%$ \\
\hline ARAGÓN & 1,41 & 1,19 & $-15,6 \%$ \\
\hline ASTURIAS & 0,43 & 0,42 & $-2,3 \%$ \\
\hline BALEARES & 0,26 & 0,59 & $126,9 \%$ \\
\hline CANARIAS & 0,20 & 0,13 & $-35,0 \%$ \\
\hline CANTABRIA & 0,22 & 0,37 & $68,2 \%$ \\
\hline C. LA MANCHA & 0,62 & 0,25 & $-59,7 \%$ \\
\hline CASTILLA-LEÓN & 0,69 & 0,45 & $-34,8 \%$ \\
\hline CATALUNA & 0,81 & 0,86 & $6,2 \%$ \\
\hline COM. VALENCIANA & 0,90 & 1,14 & $26,7 \%$ \\
\hline EXTREMADURA & 0,54 & 0,81 & $50,0 \%$ \\
\hline GALICIA & 0,29 & 0,69 & $137,9 \%$ \\
\hline MADRID & 0,36 & 0,40 & $11,1 \%$ \\
\hline MURCIA & 3,48 & 4,29 & $23,3 \%$ \\
\hline NAVARRA & 0,37 & 1,93 & $421,6 \%$ \\
\hline PAÍS VASCO & 1,01 & 4,97 & $392,1 \%$ \\
\hline LA RIOJA & 0,45 & 1,73 & $284,4 \%$ \\
\hline
\end{tabular}

Fuente: elaboración propia a partir de datos del Ministerio de Empleo y Seguridad Social (2015).

Sin embargo, los resultados de esta tabla 4 deben ser puestos en perspectiva respecto a la tabla 3. En el período de crisis (2008-2013) se produce, en términos generales, una fuerte contracción del número de empresas constituidas. No obstante, la reducción del número de empresas de economía social es proporcionalmente mayor respecto a otras formas de carácter mercantil. Se ha producido, por tanto, una caída del peso relativo de las empresas de economía social respecto al total. Dicha caída ha llevado a que el denominador del indicador Iag sea menor en la segunda etapa que en la primera. Por consiguiente, los incrementos destacados en la tabla 4 en las seis Comunidades Autónomas en las que hay una especialización en economía social en el período de crisis se producen porque la proporción de dichas formas respecto al total han caído relativamente menos que en el agregado de España.

\subsection{Mapas de distribución}

A partir de los índices Iag calculados y recogidos en la tabla 4, se elaboraron mapas para ambos períodos. Así, se pudo analizar visualmente los patrones territoriales de creación de empresas. El peso relativo de las empresas de economía social en algunas CC.AA. no se traduce necesariamente en la existencia de clusters de empresas de economía social. En el gráfico 2, se representan en verde aquellas comunidades autónomas con un Iag superior a 1 para el primer período 2002-2007. 
Gráfico. 2. Mapa del efecto cluster de economía social (2002-2007).

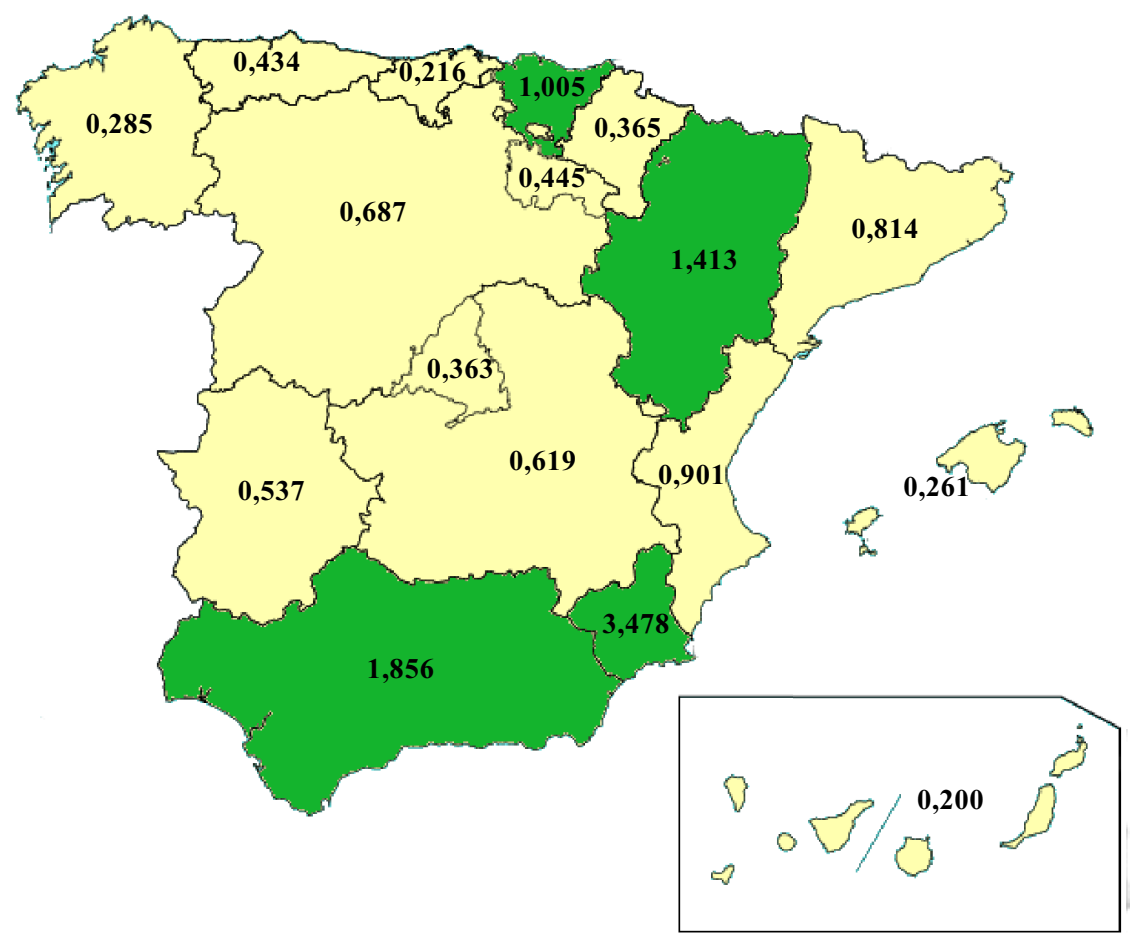

Fuente: elaboración propia.

En el gráfico 3 se observa cómo se activan la Comunidad Valenciana y Navarra en el segundo período analizado, marcando un eje continuo del País Vasco a Murcia con índices Iag superiores en todos los casos a los del período de crecimiento 2002-2007. Queda evidente que en algunas CC.AA. el peso relativo de la economía social es bajo. Además, la creación de empresas bajo fórmulas de economía social es un proceso con mayor arraigo en las comunidades mediterráneas y en la zona del País Vasco-La Rioja-Navarra. Es más, se observa notoriamente que el País Vasco es un referente en el sector industrial bajo fórmulas de economía social, y que desde el primer período analizado al segundo ha podido haber influido en regiones limítrofes como La Rioja o Navarra.

En conjunto, estos resultados son indicativos del efecto de la crisis económica sobre los patrones de creación de empresas. Así, las comunidades que incrementan su índice Iag en el segundo período con respecto al primero lo hacen porque esencialmente la creación de empresas de economía social decrece proporcionalmente menos que en el agregado de España. En resumen, comparando los mapas de los gráficos 2 y 3 , y a la vista de la evolución de las tablas 3 y 4 , estaríamos ante la evidencia de que la institución empresa de economía social se estaría replicando gracias a su mayor resistencia frente a la crisis. En cambio, no se ha constatado que la economía social haya sido el sector refugio en cuanto a 
creación de empresas, aspecto que por lo tanto no ha influido en la conformación de los cluster de economía social.

Gráfico. 3. Mapa del efecto cluster de economía social (2008-2013).

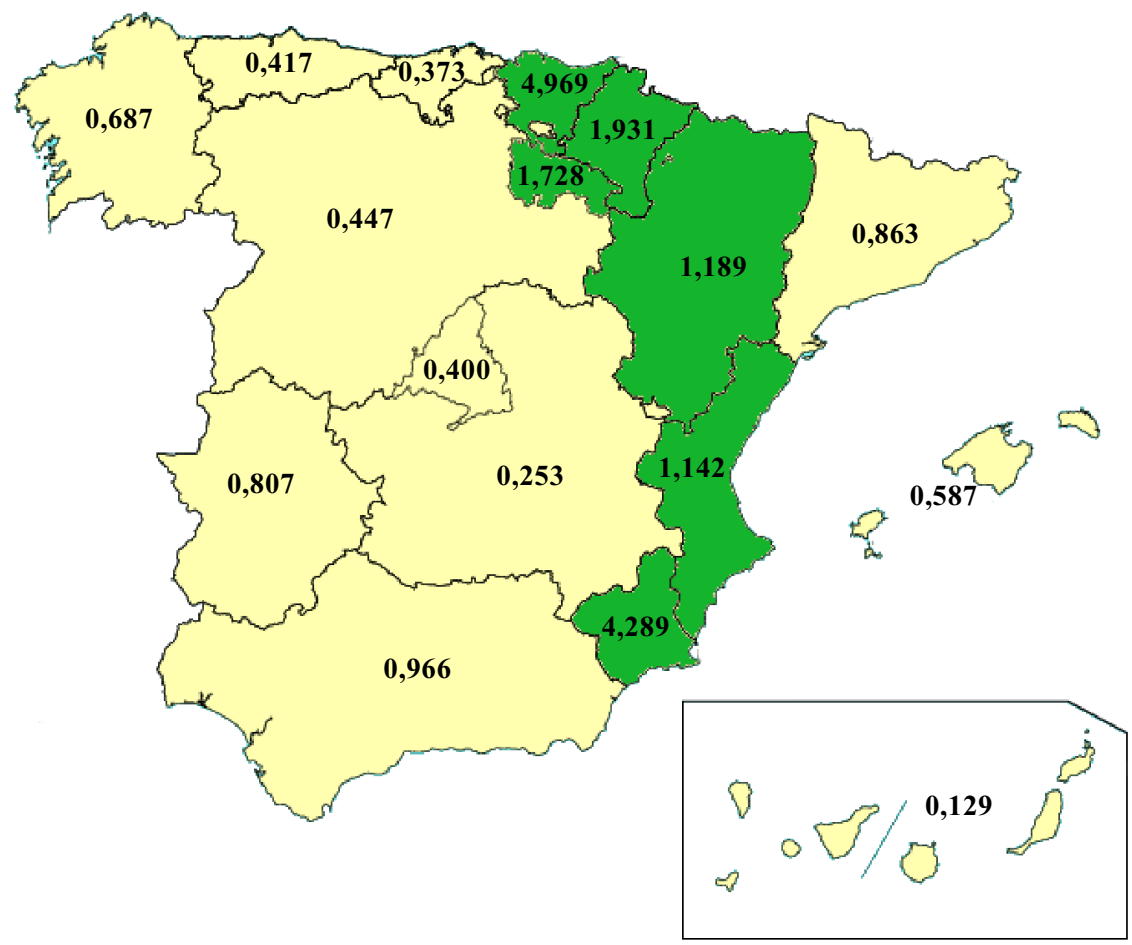

Fuente: elaboración propia.

\subsection{Asociaciones entre el coeficiente de especialización (Iag) y el PIB regional}

Llegados a este punto, resulta interesante buscar relaciones entre el carácter emprendedor de una comunidad autónoma y el crecimiento de su actividad económica medida en términos de su producto interior bruto (PIB). Para tratar la información del PIB regional se han buscado criterios homogéneos con respecto a los períodos objeto de estudio. Así, se introdujeron los valores del PIB acumulado para los períodos de crecimiento (2002-2007) y de crisis (2008-2013) y se calcularon las tasas de variación acumuladas en el total del subperíodo y las tasas medias de variación para cada subperíodo y comunidad autónoma (ver tabla 5). 
Tabla. 5. Relación entre las tasas de variación del PIB y el coeficiente de localización (Iag).

\begin{tabular}{|c|c|c|c|c|c|c|c|}
\hline \multirow{2}{*}{$\begin{array}{l}\text { COMUNIDAD } \\
\text { AUTÓNOMA }\end{array}$} & \multicolumn{2}{|c|}{$\begin{array}{c}\text { TASA ACUM. } \\
\text { VAR. PIB }\end{array}$} & \multicolumn{2}{|c|}{$\begin{array}{l}\text { TASA MEDIA } \\
\text { VAR. PIB }\end{array}$} & \multicolumn{2}{|c|}{$\begin{array}{c}\text { COEF. } \\
\text { LOCALIZACIÓ } \\
\text { N Iag }\end{array}$} & \multirow{2}{*}{$\begin{array}{c}\text { RELACIÓ } \\
\text { N ENTRE } \\
\text { TASA V. } \\
\text { Ac. PIB } \\
\text { 08/13 Y } \\
\text { Iag > } 1\end{array}$} \\
\hline & $\begin{array}{l}2002- \\
2007\end{array}$ & $\begin{array}{l}2008- \\
2013\end{array}$ & $\begin{array}{l}2002- \\
2007\end{array}$ & $\begin{array}{l}2008- \\
2013\end{array}$ & $\begin{array}{l}2002- \\
2007\end{array}$ & $\begin{array}{l}2008- \\
2013\end{array}$ & \\
\hline ANDALUCIA & $22,8 \%$ & $-8,8 \%$ & $3,81 \%$ & $-1,5 \%$ & 1,856 & 0,966 & $(-)$ \\
\hline ARAGÓN & $23,6 \%$ & $-6,9 \%$ & $3,93 \%$ & $-1,1 \%$ & 1,413 & 1,189 & $(-)$ \\
\hline ASTURIAS & $17,1 \%$ & $-10,3 \%$ & $2,84 \%$ & $-1,7 \%$ & 0,434 & 0,417 & $(-)$ \\
\hline BALEARES & $13,3 \%$ & $-3,7 \%$ & $2,21 \%$ & $-0,6 \%$ & 0,261 & 0,587 & $(-)$ \\
\hline CANARIAS & $17,0 \%$ & $-5,6 \%$ & $2,83 \%$ & $-0,9 \%$ & 0,200 & 0,129 & $(-)$ \\
\hline CANTABRIA & $15,0 \%$ & $-9,4 \%$ & $2,50 \%$ & $-1,6 \%$ & 0,216 & 0,373 & $(-)$ \\
\hline $\begin{array}{l}\text { C. LA MANCHA } \\
\text { CASTILLA Y }\end{array}$ & $28,5 \%$ & $-5,7 \%$ & $4,75 \%$ & $-1,0 \%$ & 0,619 & 0,253 & $(-)$ \\
\hline LEÓN & $17,5 \%$ & $-6,8 \%$ & $2,92 \%$ & $-1,1 \%$ & 0,687 & 0,447 & $(-)$ \\
\hline $\begin{array}{l}\text { CATALUÑA } \\
\text { COM. }\end{array}$ & $20,0 \%$ & $-7,6 \%$ & $3,33 \%$ & $-1,3 \%$ & 0,814 & 0,863 & $(-)$ \\
\hline VALENCIANA & $19,8 \%$ & $-10,3 \%$ & $3,29 \%$ & $-1,7 \%$ & 0,901 & 1,142 & $(+)$ \\
\hline EXTREMADURA & $21,4 \%$ & $-5,1 \%$ & $3,57 \%$ & $-0,8 \%$ & 0,537 & 0,807 & $(-)$ \\
\hline GALICIA & $22,0 \%$ & $-6,1 \%$ & $3,66 \%$ & $-1,0 \%$ & 0,285 & 0,687 & $(-)$ \\
\hline MADRID & $23,6 \%$ & $-1,9 \%$ & $3,93 \%$ & $-0,3 \%$ & 0,363 & 0,400 & $(-)$ \\
\hline MURCIA & $25,1 \%$ & $-6,3 \%$ & $4,18 \%$ & $-1,0 \%$ & 3,478 & 4,289 & $(+)$ \\
\hline$N A V A R R A$ & $20,2 \%$ & $-4,4 \%$ & $3,37 \%$ & $-0,7 \%$ & 0,365 & 1,931 & $(+)$ \\
\hline PAÍS VASCO & $17,3 \%$ & $-5,6 \%$ & $2,88 \%$ & $-0,9 \%$ & 1,005 & 4,969 & $(+)$ \\
\hline RIOJA (LA) & $22,0 \%$ & $-7,5 \%$ & $3,67 \%$ & $-1,2 \%$ & 0,445 & 1,728 & $(+)$ \\
\hline
\end{tabular}

Fuente: elaboración propia a partir de datos del INE (2015).

Bajo la tesis de que las formas societarias de economía social actúen como refugio durante situaciones desfavorables por las características que las definen y por las ventajas fiscales y sociales que les confiere la normativa, cabría esperar una asociación entre decrecimiento de PIB y aumento en el índice Iag. Esta primera premisa se cumple en casi todas las comunidades autónomas, a excepción de Asturias, Canarias y las dos Castillas. En Andalucía el valor del Iag es superior a 1,8 en el primer subperíodo, pero no en el segundo. En Aragón, es superior a la unidad en ambos subperíodos. De hecho, si ahora se refina más el análisis, sólo 6 comunidades tienen índices Iag superiores a 1 en la fase de crisis (ver gráfico 3 ).

Si se relaciona el coeficiente de localización con la tasa media de crecimiento del PIB se obtienen los gráficos 4 y 5. Estos gráficos establecen una ordenación en cuatro grupos: Iag $>1$ con tasa de variación media del PIB inferior a la media estatal $(-,+)$; el caso contrario con Iag $<1$ y tasa de variación superior a la media estatal $(+$, 
-). Y las casillas donde coinciden, ya sea de manera positiva o negativa el Iag y la tasa de variación media del PIB $[(+,+)$ y $(-,-)]$.

Gráfico 4. Relación entre la tasa media de variación de PIB con respecto al coeficiente de localización Iag (2002-2007).

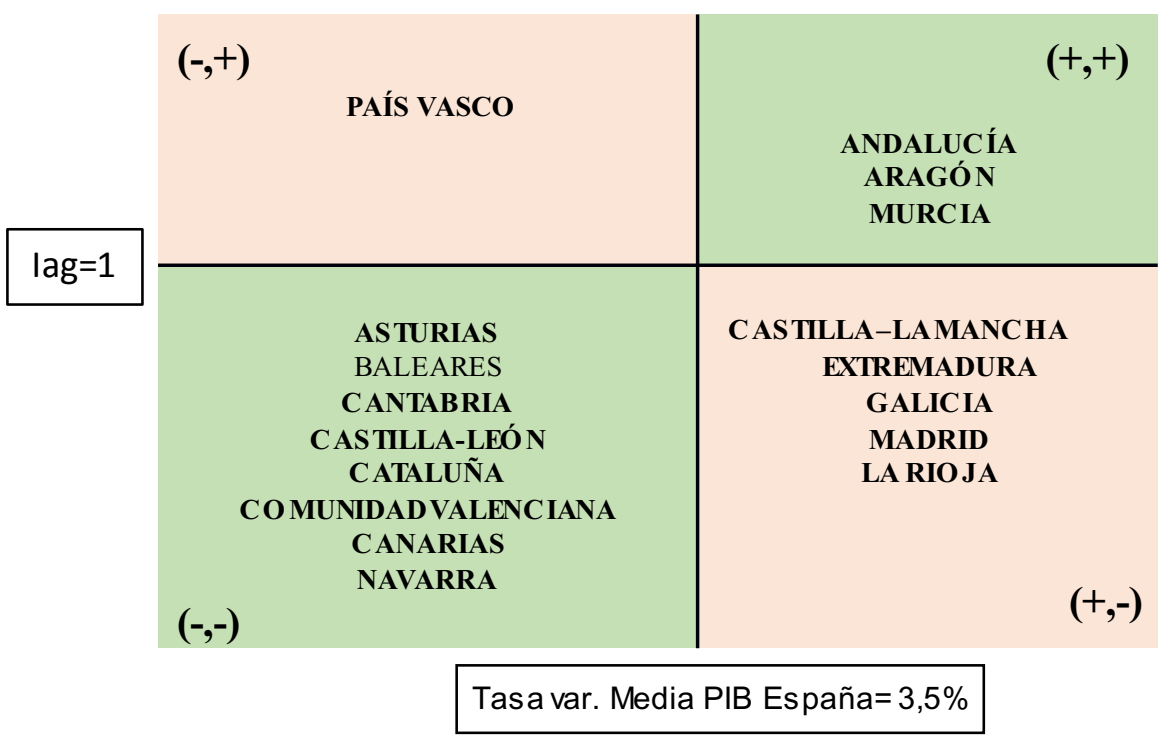

Fuente: elaboración propia.

Se observa que en el período de crisis (gráfico 5) hay un aumento de comunidades autónomas con índice Iag mayor que uno. Pero quizás lo más relevante es que en fases de crecimiento de la economía, las empresas optan por formas de carácter mercantil, mientras que en las fases de recesión aumenta el índice Iag debido a que el peso relativo de creación de empresas de economía social decae menos en dichas comunidades de lo que sucede en el agregado de España. Solo Murcia y País Vasco mantienen este comportamiento emprendedor de carácter social en ambos períodos. En el lado contrario, la propensión a emprender bajo formas mercantiles es la predominante en la mayor parte de CC.AA., tanto en fase de recesión como de crecimiento económico. Estos hallazgos difieren en cierta medida de los de Díaz y Marcuello (2010), quienes encontraron que la influencia de la evolución del PIB sobre el empleo era menor en las sociedades cooperativas que sobre el conjunto de la economía española. Ese hallazgo para el conjunto parece estar influido por variaciones regionales, como así encontraron también Ríos et al. (2014). De hecho, Clemente et al. (2009) señalaba un cambio de tendencia estructural en el empleo de las cooperativas observable desde el 2002, con una dinámica similar a la del resto de empresas: un detrimento en el empleo durante etapas recesivas, lo cual impactaría también en la generación de riqueza en las regiones (PIB). Por tanto, es interesante observar también si existe dependencia espacial, aspecto que se analiza en el apartado siguiente. 
Gráfico. 5. Relación entre la tasa media de variación de PIB con respecto al coeficiente de localización Iag (2008-2013).

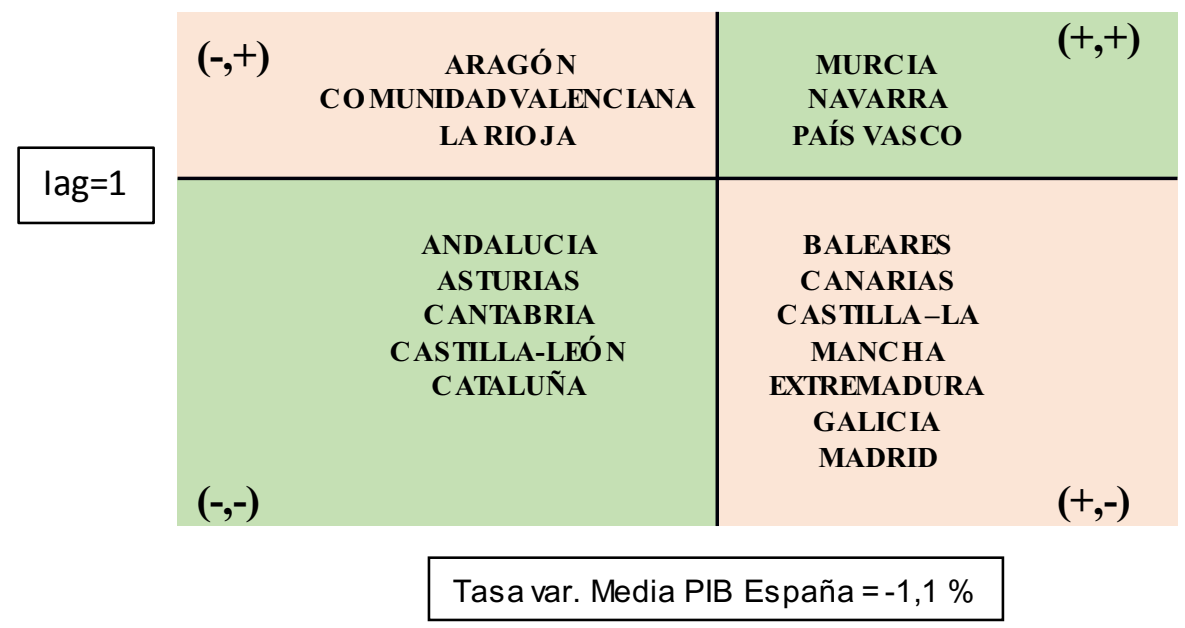

Fuente: elaboración propia.

\subsection{Análisis geoespacial de creación de empresas cooperativas}

En este apartado se analizan los procesos de correlación espacial a través del Análisis Exploratorio de Datos Espaciales (AEDE), para así evaluar la existencia de distribuciones espaciales que permitan identificar clusters de empresas de economía social y esquemas que sugieran la existencia de estructuras espaciales no aleatorias (Chasco, 2003).

En el análisis LISA (índice de Asociación Local) se evidencia que en el período 2002-2007 sólo se constatan aglomeraciones espaciales de empresas mercantiles ya que no hay ninguna comunidad autónoma con un índice de agrupación superior a 1 y cuyos vecinos tengan rangos semejantes o superiores a este valor, por lo que el proceso emprendedor en economía social tiene el carácter de concentrado espacialmente. Para empresas mercantiles tiende a ser difundido, ya que existen 6 regiones cuyas comunidades vecinas toman valores del índice de agrupación en el mismo rango de valor (Iag inferior a uno).

Para el período 2002-2007 (gráfico 6), el índice de Moran toma un valor de 0,134 por lo que se puede decir que existe una autocorrelación espacial positiva, pero el valor explicativo del índice es relativamente bajo. Dicho valor señala que solo explica el 13,4\% de los datos geo-referenciados, por lo que la autocorrelación espacial es limitada. El análisis del mapa indica que no hay ninguna comunidad autónoma con índice superior a 1 que tenga todos los territorios vecinos con pesos del índice ( $I a g$ ) de la misma categoría, por lo que no se evidencia la existencia de clusters espaciales en economía social, solo la existencia de contextos mixtos (outliers). 
Gráfico. 6. Diagrama de dispersión e índice de Moran (2002-2007).

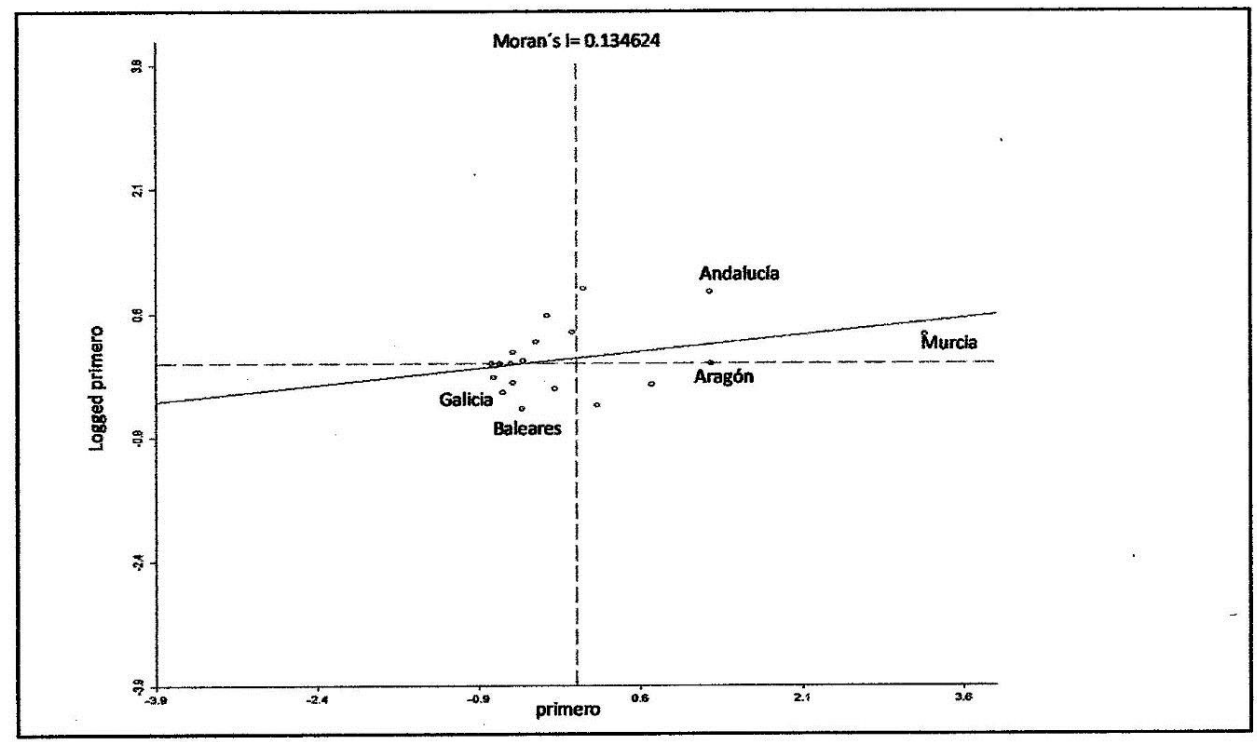

Fuente: elaboración propia.

En el período 2008-2013 (gráfico 7) el índice de Moran toma un valor prácticamente $0(0,03)$ por lo que se constata que no hay autocorrelación espacial. Por tanto, los comportamientos de un territorio con respecto al emprendimiento en empresas de economía social resultan aleatorios y no se corresponderían con ningún patrón de comportamiento imitador a lo largo del tiempo y de la geografía. 
Gráfico. 7. Diagrama de dispersión e índice de Moran (2008-2013).

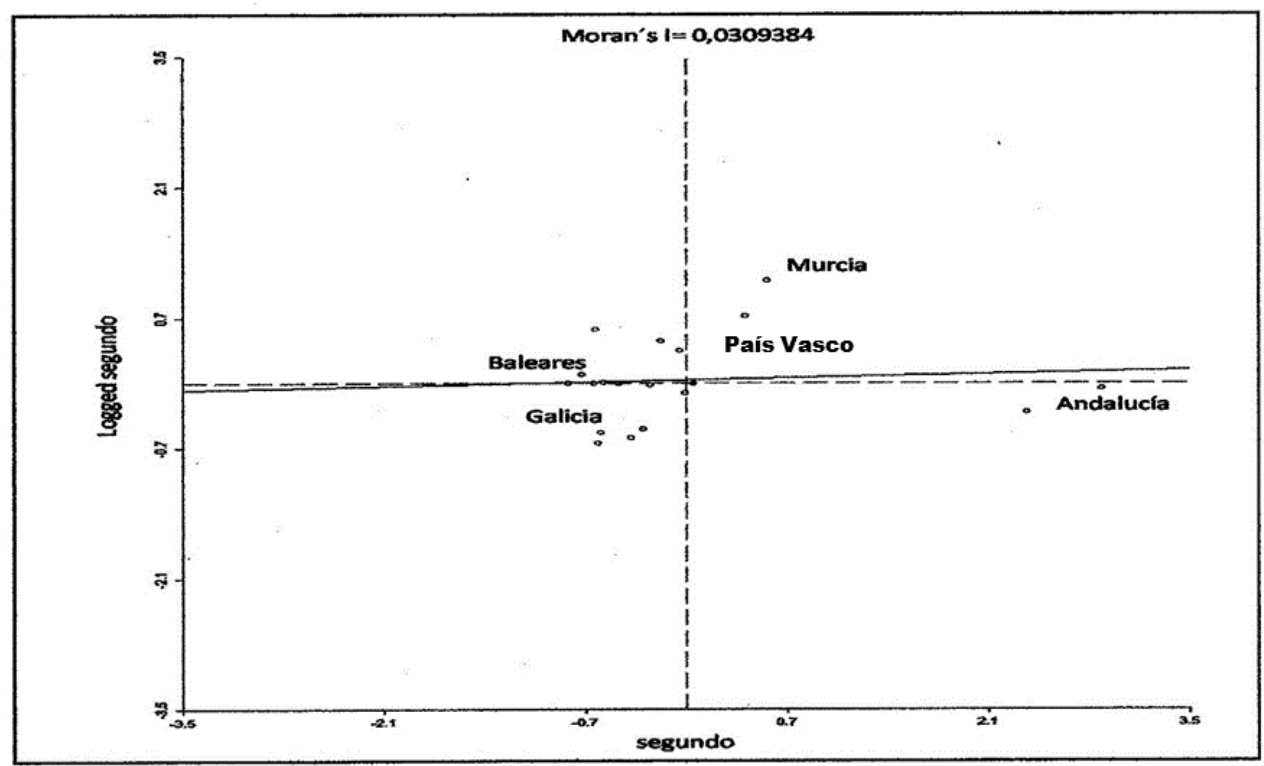

Fuente: elaboración propia.

El análisis LISA (gráfico 8) trabaja con los valores obtenidos del Índice de Moran y analiza la existencia de comportamientos relacionados entre territorios vecinos. A pesar del anterior comportamiento aleatorio, el análisis LISA evidencia la existencia de un cluster emprendedor en economía social en Navarra (ver también gráfico 4). En esta técnica de análisis, el concepto cluster se contempla cuando un territorio tiene como vecinos territorios con pesos del valor de agrupación (Iag) semejantes, en este caso mayor que 1. 
Gráfico. 8. Mapa LISA y grado de significación del cluster.

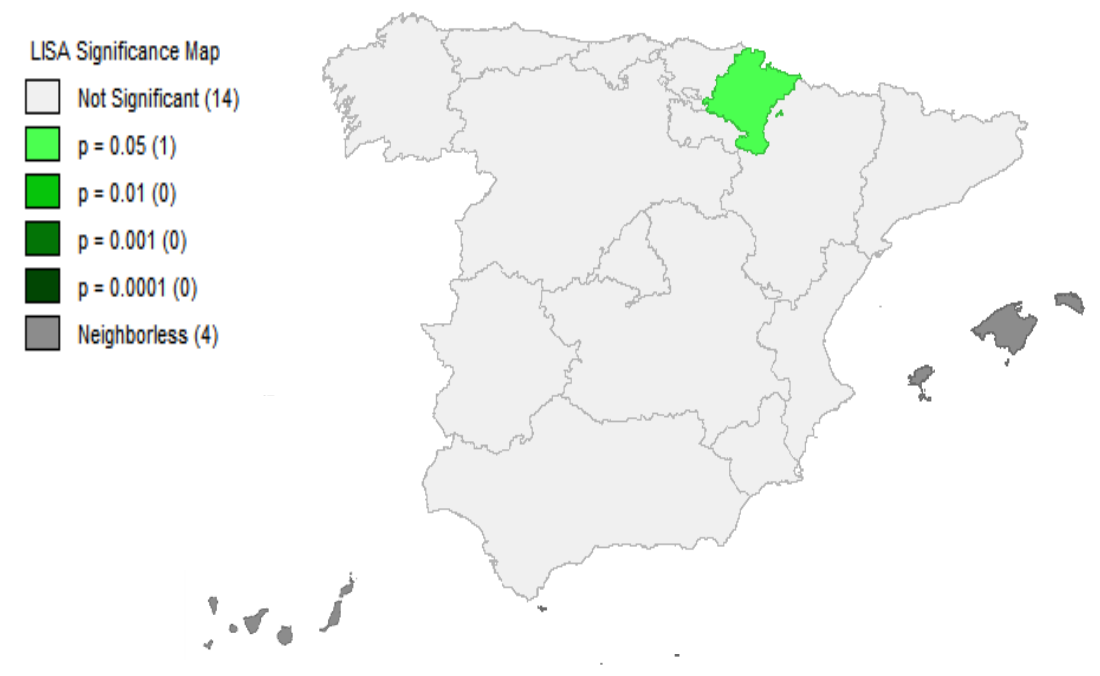

Fuente: elaboración propia.

Atendiendo a la dinámica de los datos, más que considerar que Navarra es un cluster de empresas de economía social, sería más bien consecuencia de las influencias del País Vasco, que muestra en todo el período un papel destacado en el ámbito de la economía social, además de contar con otros vecinos con valores superiores a 1 en el índice Iag.

Dicho de otro modo, se produce un punto hot spot cuando un territorio se encuentra rodeado de territorios con peso similar para el indicador (Iag) y tienen índice de Moran igual o muy próximo a cero. Esto indica que no existe autocorrelación espacial y que la existencia de este punto hot spot no es más que consecuencia de un proceso aleatorio, más relacionado con cuestiones del entorno que realmente por la capacidad de difundir comportamientos emprendedores hacia territorios vecinos. Por ello, es conveniente interpretar el dato desde la perspectiva de difusión del espíritu emprendedor en economía social desde las comunidades vecinas, que evidencian tradición en este tipo de empresas, hacia un territorio sometido a las dificultades que genera la crisis y que busca en estas empresas una forma de poder defenderse de la situación y generar autoempleo.

\section{Conclusiones}

El objetivo de este trabajo era analizar si existía algún patrón espacial de creación de empresas de economía social en España, así como estudiar su evolución temporal (2002-2013) mediante el establecimiento de dos etapas diferenciadas, una de crecimiento y otra de profunda crisis generalizada. Para tal fin, se han realizado diferentes contrastes entre empresas de economía social y empresas de fórmulas mercantiles más habituales $(\mathrm{SL}, \mathrm{SA})$ respecto diferentes indicadores. 
Los resultados evidencian que se ha producido una reducción importante en los procesos de creación de empresas y que éste ha sido más acusado entre las empresas que hemos denominado como de economía social (-60\%) que entre las empresas mercantiles (-20\%). Esa primera conclusión contradice estudios previos (Ben-Ner, 1998; Rusell y Hanneman, 1992, entre otros) que sugieren que la creación de empresas de economía social es contra-cíclica y actúa como sector refugio en épocas de crisis.

Además, nuestro estudio muestra que ese patrón es más diverso y heterogéneo cuando el análisis se hace a nivel autonómico y sectorial, donde destaca una mayor actividad emprendedora en las CC.AA. de Andalucía, Murcia, Navarra y País Vasco y en el sector servicios. Algunas de las razones que explicaría esto último serían el menor coste de inversión y puesta en marcha de la actividad. Por otro lado, se observa una importante reducción generalizada en el número de empresas creadas bajo fórmulas de economía social en la actividad de construcción en consonancia con la situación de esta industria en la etapa de crisis.

Estos resultados más generales evidencian que en España la creación de empresas de economía social se distribuye de forma bastante aleatoria en tiempo y espacio. Por ello, se podría decir que la influencia de la tradición cultural o el marco relacional que se da en el contexto de las CC.AA. parece ser bastante limitado. Eso significa que la existencia de normativas específicas que contemplan la singularidad autonómica respecto a la economía social no siempre se ha traducido en términos de mayor número de empresas de economía social. En otras palabras, se podría afirmar que a la hora de constituirse una nueva empresa los emprendedores siguen más una estrategia de imitación basada en hacer lo que hace la mayoría (apuesta por las sociedades mercantiles) en lugar de otras alternativas como es la economía social. Por consiguiente, se pueden aventurar resultados aleatorios en el desarrollo normativo de la economía social.

Estas conclusiones sirven, a nivel político, como estímulo para el desarrollo de nuevas iniciativas tendentes a difundir el emprendimiento social, ya que durante este último periodo las acciones de promoción hasta ahora desarrolladas en las diferentes CCAA se han mostrado ineficaces. Para esa tarea de promoción y fomento se sugiere la implementación de otros modelos como el de los cluster de empresas de economía social. Su aplicación permitiría la creación de un contexto relacional óptimo (ecosistema) que favorecería la cooperación entre sus actores, para así conseguir recursos claves, ahorrar costes o acceder a otros mercados.

Nuestro trabajo no está exento de limitaciones derivadas de la base de datos, período analizado y técnicas empleadas. Además, pueden existir algunas distorsiones originadas por la sobredimensión de algunas capitales de provincia como son Madrid o Barcelona. Futuras investigaciones deberían de replicar este estudio incluyendo otros aspectos relativos al entorno y a cada organización individual.

A pesar de estas limitaciones, los resultados obtenidos pueden servir de base para posteriores investigaciones tendentes a evaluar el emprendimiento en economía social por subsectores de actividad. En este sentido, una escala espacial menor como pueden ser las provincias (NUT-3) o incluso las comarcas o agregaciones de municipios, podría explicar con más claridad el porqué de este comportamiento aleatorio en la creación de empresas de economía social en 
situaciones de declive económico. También se aconseja el uso de otras técnicas estadísticas, tales como los conjuntos borrosos (fuzzy set), ya que la organización administrativa en CC.AA. puede no corresponderse siempre con relaciones intraterritorios.

\section{Referencias bibliográficas}

Anderson, W. P. (2012) Economic geography. Routledge.

Anselin, L. (1995) Local Indicators of Spatial Association-LISA. Geographical Analysis, vol. 27, $\mathrm{n}^{\circ} 2$, pp. 93-115.

Anselin, L. (2004) GeoDa 0.95i Release Notes. Urbana-Champaign, IL: Spatial Analysis Laboratory (SAL) Department of Agricultural and Consumer Economics, University of Illinois.

Becatini, G. (2002) Del distrito industrial marshaliano a la teoría del distrito contemporáneo. Investigaciones Regionales $\mathrm{n}^{\circ} 1$, pp 9-32.

Bel-Durán, P., Fernández-Guadaño, J., Lejarriaga-Pérez De Las Vacas, G. y Martín-López, S. (2016) La iniciativa emprendedora como base para la creación de empresas de participación. Un instrumento para la innovación social. Cooperativismo y Desarrollo, vol. 24, no 108, pp. 121-141.

Ben-Ner, A. (1988) Comparative empirical observations on worker-owned and capitalist firms. International Journal of Industrial Organization, vol. 6, $\mathrm{n}^{\mathrm{o}} 1$, pp. 7-31.

Cantarero, S.; González-Loureiro, M. y Puig, F. (2013) El efecto "economía social" en la supervivencia empresarial. Ciriec-España, Revista de Economía Pública, Social y Cooperativa, vol. 78, pp. 175-200.

Chasco, C. (2003) Econometría espacial aplicada a la predicción-extrapolación de datos microterritoriales, Dirección General de Economía y Planificación, Madrid.

Chaves, R. y Monzón, J.L. (2012) Beyond the crisis: the social economy, prop of a new model of sustainable economic development. Service Business: An international Journal, vol. 6, no. 1, pp. 5-26.

Clemente, J.; Díaz, M. y Marcuello, C. (2009) Sociedades cooperativas y sociedades laborales en España: estudio de su contribución a la creación de empleo y al crecimiento económico. REVESCO. Revista de Estudios Cooperativos, $\mathrm{n}^{\circ}$ 98, pp. 35-69.

Cromley, R. G., y Hanink, D. M. (2012) Focal location quotients: specification and applications. Geographical Analysis, vol. 44, nº. 4, pp. 398-410.

Delgado, M.; Porter, M. E. y Stern, S. (2010) Clusters and entrepreneurship. Journal of Economic Geography, vol. 10, no 4, pp. 495-518.

Díaz, M. y Marcuello, C. (2010) Impacto económico de las cooperativas. La generación de empleo en las sociedades cooperativas y su relación con el PIB. Ciriec-España, Revista de Economía Pública, Social y Cooperativa, vol. 67, p. 23-44.

Glaeser, E. L., Kerr, W. R. y Ponzetto, G. A. (2010) Clusters of entrepreneurship. Journal of Urban Economics, vol. 67, n ${ }^{\circ}$ 1, pp. 150-168.

González-Loureiro, M.; Puig, F. y Moyano, J. (2014) Ownership structures and Survival: Democracy vs. Hierarchy, Paper presented at EURAM Conference.

Gordon, I., y McCann, P. (2005) Clusters, innovation and regional development: an analysis of current theories and evidence, en Karlsson, Johansson \& Stough. Industrial clusters and inter-firm networks, pp. 29-57, ed. Edward Elgar Pub. Ld.

Granovetter, M. S. (1973) The Strength of Weak Ties. American Journal of Sociology, vol. $78, n^{\circ} 6$, pp. 1360-1380. 
Grávalos, M.A. y Pomares, I. (2001) La adaptación de las sociedades laborales a la evolución del ciclo económico. Un estudio empírico para las diferentes comunidades autónomas. Ciriec-España, Revista de Economía Pública, Social y Cooperativa, vol. 38, pp. 33-55.

Kelley, D. J., Singer, S., y Herrington, M. (2012) The global entrepreneurship monitor. 2011 Global Report, GEM 2011, vol. 7.

Knight, F. H. (1921) Risk, uncertainty and profit. New York: Hart, Schaffner and Marx.

Marshal, A. (1923) Industry and trade, The MIT Press, Cambridge.

Martín, S., Fernández, J., Bel, P. y Lejarriaga, G. (2013) Necesidad de medidas para impulsar la creación de las empresas de participación desde los diferentes niveles de enseñanza. Ciriec-España, Revista de Economía Pública, Social y Cooperativa, vol. 78, pp. 71-99.

Meyer, K. E. (2015) Context in Management Research in Emerging Economies. Management and Organization Review, vol. 11, nº 03, pp. 369-377.

Monzón, J.L., Chaves, R. (2012) La Economía Social en la Unión Europea. Informes de la Unión Europea.

Moran, P. A. P. (1950) Notes on continuous stochastic phenomena. Biometrika, vol. 37, $\mathrm{n}^{\circ} 1 / 2$, pp. 17-27.

North, D.C. (1993) Instituciones, cambio institucional y desempeño económico. Fondo de Cultura SA. México.

Pérez, M.C. y Valiente, L. (2015) Impacto territorial del autoempleo en la economía social en España. Ciriec-España, Revista de Economía Pública, Social y Cooperativa, vol. 83, pp. 83-114.

Pérotin, V. (2006) Entry, exit, and the business cycle: Are cooperatives different?. Journal of Comparative Economics, vol. 34 n 2, pp. 295-316.

Porter, M. (1999) Clusters and Competition:New agendas for companies, governments and institutions. Harvard Bussiness School Press. Harvard.

Potter, A. y Watts, H. D. (2011) Evolutionary agglomeration theory: increasing returns, diminishing returns, and the industry life cycle. Journal of Economic Geography, vol. $11, \mathrm{n}^{\mathrm{o}} 3$, pp. 417-455.

Puig, F.; García-Mora, B. y Santamaría, C. (2013) The Influence of Geographical Concentration and Structural Characteristics on the Survival Chance of Firms. Journal of Fashion Marketing and Management, vol. 17, $\mathrm{n}^{\mathrm{o}}$ 1, pp. 5-20.

Puig, F.; González-Loureiro, M., y Ghauri, P. N. (2014) Internationalisation for Survival: The Case of New Ventures. Management International Review, vol. 54, no 5, pp. $653-$ 673.

RAE-Real Academia Española (2014) Diccionario de la lengua española. 23a ed, RAE, Madrid.

Ríos, M. S., Perdiguer, M. F., y Solé, T. T. (2014) Un análisis del comportamiento cíclico de las cooperativas y sociedades laborales españolas y su relación con la actividad económica. REVESCO. Revista de Estudios Cooperativos, $\mathrm{n}^{\circ}$ 115, pp. 7-29. DOI: 10.5209/rev_REVE.2014.v115.45279.

Russell, R. y Hanneman, R. (1992) Cooperatives and the business cycle: The Israeli case. Journal of Comparative Economics, vol. 16, pp. 701-715.

Staber, U. (1993) Worker cooperatives and the business cycle: are cooperatives the answer to unemployment?. The American Journal of Economics and Sociology, vol. 52, $\mathrm{n}^{\mathrm{o}} 2$, pp. 129-143. 
Staber, U. (2001) Spatial proximity and firm survival in a declining industrial district: the case of knitwear firms in Baden-Wurttemberg. Regional Studies, vol. 35, nº 4, pp. 329 341. 